\title{
Servikal spondilotik miyelopati ve radikülopati: doğal seyir ve klinik sunum
}

\section{Cervical spondylotic myelopathy and radiculopathy: natural history and clinical presentation}

\author{
Seçkin Sarı ${ }^{1}$, Güray Altun ${ }^{2}$ \\ ${ }^{1}$ Fulya Ortopedi ve Omurga Merkezi, İstanbul \\ ${ }^{2}$ S.B.Ü. Ümraniye Eğitim ve Araştırma Hastanesi, Ortopedi ve Travmatoloji Kliniği, İstanbul
}

\begin{abstract}
Ilerleyen yaşla birlikte servikal omurgada görülen dejeneratif değişiklikler, servikal spondiloz olarak isimlendirilir. $\mathrm{Bu}$ değişikliklerin nöronal yapılarda bası ve inflamasyon geliştirmesi üzerine, boyun ağrısı, radikülopati, miyelopati gibi klinik bulgular ortaya çıkmaktadır. Süreç içerisinde kronikleşen bası, hem radyolojik hem de fonksiyonel kalıcı değişikliklere ve nörolojik kötüleşmeye neden olabilmektedir. Patofizyolojisinde nöral yapılara direkt bası görülür ve vasküler dolaşımda bozulmaya bağlı tablo ilerleyici olarak devam eder. Servikal spondilotik radikülopati ve miyelopatinin tedavisinde değişik görüşler olmakla birlikte, en çok tartışma cerrahi zamanlama açısındandır.
\end{abstract}

Anahtar sözcükler: servikal miyelopati; doğal seyir; servikal radikülopati

\begin{abstract}
Age related degenerative changes in cervical spine are called cervical spondylosis. These degenerative changes that result in compression and inflammation of the neural structures reflect as radiculopathy, myelopathy and neck pain. The chronic compression causes persistent neurological and radiological changes, become irreversible, and at the same time neurological deterioration is seen. In pathophysiology, direct compression leads to vascular insufficiency, and clinical worsening. Although there are different opinions in the treatment of cervical spondylotic myelopathy and radiculopathy, main discussion is about timing of surgery.
\end{abstract}

Key words: cervical myelopathy; natural history; cervical radiculopathy ervikal disk ve faset eklemlerin dejeneratif değişiklikleri, yetişkinlerde sık görülür ve çoğunlukla asemptomatik seyreder. Spondiloliz terimi, spinal kolonun artan yaşla ilişkili dejeneratif değişikliklerini tanımlar. ${ }^{[1]} \mathrm{Bu}$ dejeneratif değişikliklere bağlı olarak, servikal köklerde bası ve inflamasyon sonucu, motor ve duyu arazı olsun ya da olmasın hissedilen ağrıya "servikal spondilotik radikülopati" (SSR), bası ve inflamasyon spinal kordda olursa da, oluşan tabloya "servikal spondilotik miyelopati" (SSM) denmektedir. SSM, yaşılarda travmatik olmayan spastik paraparezi, kuadriparezinin ve spinal disfonksiyonun en sık nedenidir. ${ }^{[2]}$

Klinik olarak bakıldığında, servikal spondiloz üç şekilde ortaya çıkmaktadır. Illki aksiyel boyun ağrısıdır; vertebral kolon boyunca ilgili kas gruplarında yayılır.
İkincisi servikal radikülopatidir ve kolda yayılan ağrıya ek olarak duyusal veya motor fonksiyonel kayıp görülür. Üçüncü olarak ise yürüyüş bozukluğu, ince beceri kaybı, ellerde uyuşukluk ve spastik kas güçsüzlügü ile giden servikal miyelopatiyi sayabiliriz. ${ }^{[3]}$

\section{PATOFIZYOLOJi}

\section{Spondiloliz}

Spondilolitik yakınmalar ve patolojileri başlatan tablo, genel olarak foraminal ve spinal kanalda olan daralmadır. Süreç, diskin kuruması/susuzlaşması ile başlar. ${ }^{[4]}$ Servikal diskler, lordozu sağlamak için ventralden dorsale doğru yükselir. Ventral anulus Tip 1 kollajenden oluşan çok katlı bir yapıyken, dorsal kısım ince fibriller bir yapıdadır. ${ }^{[5]}$ Nükleusun içeriğindeki

- İletişim adresi: Dr. Seçkin Sarı, Dikilitaş Mah. Ayazmadere Cad. Yeşilçimen Sok. No: 9/3 Kat: 3, Fulya, Beşiktaş, İstanbul Tel: 0212 - 2276338 e-posta: drssari@gmail.com

- Geliș tarihi: 5 Nisan $2017 \quad$ Kabul tarihi: 5 Nisan 2017 
glukozaminoglikan proteoglikan ve polisakkaritler su tutar. Su içeriğinin yüksek olması, diske elastik ve viskoz özellikler kazandırır. Yaşın ilerlemesiyle birlikte, nükleusun su içeriğinde azalma olur. Bu durum, elastikiyet ve yük taşıma kapasitesinde düşüşe neden olur ve gelen yüklere cevap veremeyen anulus fibrozus, dejeneratif süreç içerisinde kanala doğru taşma yapmaya başlar. Disk yüksekliğindeki kayıplar, fizyolojik lordozun kaybına neden olur. Biyomekanik olarak yüklenmedeki bu değişim, ventral yüzdeki yüklenmeyi arttırıp servikal bölgeyi kifoza zorlar. Bu süreçte, faset eklem kapsülü ve ligamentum flavum kanala doğru katlanır ve daralmayı arttııı. Gelen yüklerle başa çıkılmaya çalışırken oluşan aktivite, vertebra cisminde, faset eklemde ve unkovertebral eklemde osteofit oluşumuna neden olur.

\section{Radikulopati}

Kollarda gelişen radiküler bulgular, servikal sinir köklerinden kaynaklanmaktadır. Hareketleri servikal segmentlerde olan spondolitik değişikliklere bağı ılarak, disk yüksekliklerinde kayıp, disk mesafesinde taşmalar, dejenere faset eklem kapsülü görülür, hipertrofik ligamentum flavum sıkışmayı arttırır; sürece dahil olan, disk sınırında, faset ve unkovertebral eklemdeki osteofitlerle beraber, belirgin foraminal stenoz ve radikülopati oluşur. ${ }^{[6]}$

Oluşan osteofitler, aynı zamanda sinir köklerinin kan akımına etki eder; bası altındaki radiküler arterlerde oluşan spazm nedeniyle kökün kan akımında yetersizlik oluşur; ek olarak, basıya bağlı venöz dönüşteki yavaşlanmayla birlikte, kökte ödem oluşur ve tablo daha da ağırlaşır. ${ }^{[7]}$

Sinir kökünde oluşan mekanik deformasyon, motor ve duysal defisite neden olur. Oluşan radiküler ağrı, tam olarak tek nedenli değildir. Ancak, ağrıya genel olarak oluşan bası ve inflamasyonun neden olduğu bilinmektedir. Sıkışmış sinir kökündeki damar geçirgenliğinde artış, oluşan ödemin nedeni olarak gösterilmektedir. Kronikleşen ödemle birlikte kökte oluşan fibrozis, köke bağlı ağrının daha da artmasına neden olur. Bu süreçte, duyusal nöronlardan salgılanan substance-p somatostatin gibi nörojenik ve disk dokusundan salınan bradikinin serotonin gibi nörojenik olmayan mediyatörler, inflamatuvar cevabın daha da artmasına yol açar. ${ }^{[8,9]}$

\section{Miyelopati}

Miyelopati oluşumunda sorunlu olan ana olay, spinal kanal çapının daralmasıdır. Unkovertebral ve faset ekleminin arasında olan sıkışma radikülopati oluştururken; vertebral cismin osteofitleri, taşmış disk, ossifiye
PLL (posterior longitudinal bağ) veya katlanmış ligamentum flavum arasında oluşan sıkışma miyelopatiye neden olur. Normal yetişkinlerde spinal kanal ön-arka çapı 17-18 mm, sagittal çap ise $10 \mathrm{~mm}$ 'dir. Yapılan çalışmalar, $16 \mathrm{~mm}$ üstünün miyelopati açısından düşük risk olduğunu belirtmiştir. Panjabi, bu değeri 14,8 mm olarak belirtmiştir. ${ }^{[10]}$

Dejeneratif değişiklikler dışında, servikal segmentin hareketleri de spinal kanal çapında değişikliklere neden olur. Boynun hiperekstansiyonu, ligamentum flavumu öne doğru katlayarak spinal kanalı daraltır. Murano, fleksiyon ve ekstansiyonun spinal kanal çapında 2 mm'lik değişime neden olduğunu belirtmektedir. Vertebralardaki angülasyon ve translasyon, fleksiyon ve ekstansiyon sırasında kanalın dinamik olarak daralmasına neden olur. İnstabil vertebralarda ekstansiyon sırasında, retrolistezik vertebranın inferoposterior sınırı ile bir üst vertebra laminasının üst köşesi arasında kord şıkışabilir. Yine boynun fleksiyonu sırasında öne olan kayma, kayan vertebra cismi ile bir üst segmenteki lamina arasında sıkışır. ${ }^{[11]}$ Bu duruma sıkışma fenomeni denir. Bir diğer biyomekanik sorun, servikal vertebral kolondaki kifoza bağlı olarak spinal kordun anteriordaki yapının üzerinde gerilmesidir; bu duruma "sagittal bowstring effect" denir. Bu durumda yapılacak bir laminektomi, ventral kifotik segmentin basısına bağlı olarak, üst ve alt laminalar arasında kanalın sıkışmasına ve semptomların artmasına ya da rahatlamamasına neden olur. ${ }^{[12]}$

Miyelopati gelişiminden sorumlu olan darlık ve baskı, aynı zamanda lokal kan akımına da etki eder. Kan akımındaki bu yetmezlik, spinal kordda iskemiye neden olur. Hakuda ve Wilson, köpek servikal omurgalarında yaptıkları çalışmada, anterior spinal kordda bası ve vasküler yetmezliğin beraber olarak miyelopatiden sorumlu olduğunu bildirmişlerdir. ${ }^{[13]}$

Vasküler kan akımındaki bu bozulma spinal kordda, özellikle iskemiye en duyarlı bölüm olan gri maddede nekroz ve kavitasyonlara neden olur. Bu kronik iskemi süreci dışında oluşan akut miyelopati durumlarında ise, sıklıkla bası altındaki arterin trombozu suçlanmaktadır. ${ }^{[7,14]}$

Miyelopatiye hücresel düzeyde bakacak olursak; özellikle oligodendrositler, iskemiye en hassas hücrelerdir. Öncelikli görevi miyelin kılıf oluşturmak olan bu hücrelerin iskemi nedeniyle nekroz ve apoptozu, demiyelizasyon ve geri dönüşsüz nörolojik defisitten sorumlu tutulmaktadır. ${ }^{[15,16]}$ Yu ve arkadaşları yaptıkları çalışmada, C2-C3 seviyesinde ossifiye flavum oluşturdukları farelerde ilerleyici bir paralizi geliştiğini ve bu kronik iskemi durumunun oligodendrosit ve nöronlardaki apoptozise neden olduğunu bildirmişlerdir. ${ }^{[17]}$ 
Moleküler düzeyde serbest radikal oluşumu hücre hasarı ve glutaminerjik toksitite, servikal miyelopatide rol oynamaktadır. Kortikospinal yolaklardaki erken demiyelizasyonu, ön boynuz hücrelerindeki ölüm takip eder. Hasarlanma, bası seviyesinin kaudalinde olur. Devamında oluşan santral gri maddedeki kavitasyon ve nekroz, geç dönem bulgularıdır ve sürecin kronik olduğunu gösterir. ${ }^{[18]}$

\section{KLINIK}

\section{Öykü}

Servikal spondiloz süreci başladığında, hasta karşımıza üç tablo ile başvurur: boyun ağrısı, radikülopati ve miyelopati.

Saskatchewan'ın yaptığı çalışmada, erişkinlerde hayat boyunca boyun ağrısı insidansı \%66 olarak bulunmuştur ve bunların \% 5 'inde bu ağrı şiddetli ve günlük işlerini etkileyecek boyuttadır. ${ }^{[19]}$ Spondiloz nedeniyle boyun ağrısı, herhangi bir kolaylaştırıcı durum olmaksızın başlayan ağrıdır ve sıklıkla disk dejenerasyonuna bağlıdır. ${ }^{[20]}$ Bunun dışında, ağrı dejeneratif faset eklemlerine bağlı olarak da gelişebilir. Muayene sırasında ayırıcı tanı, ilgili fasetin sorunlarının yansıdığı vücut bölgeleri göz önünde bulundurularak yapılabilir. ${ }^{[21]}$ Yapılan bir çalışmada, spondiloliz nedeniyle konservatif tedavi edilen hastaların üç aylık takiplerinde, hastaların \%29'unda tam rahatlama, \%49'unda kısmi iyileşme ve \%22'sinde herhangi bir değişim olmadığı bulunmuştur. ${ }^{[22]}$

ilk defa boyun ağrısı çeken hastaların büyük kısmında, semptomlar belirgin olarak kendiliğinden geçer; ağrısı devam eden ve bunun için ilaç tedavisi kullanan hastalara bakıldığında, bu grubun \%25'inde şikayetlerin giderek arttığı görülür. Bu hastaların ağrılarının diskojenik ve/veya faset ya da başka bir patoloji kaynaklı ağrıdan ayrımı için ileri tetkik gerekir.

Radikülopati, genel olarak ilgili kökün dermatomal sahasında unilateral veya bilateral, simetrik veya asimetrik olarak oluşur. Elli beş yaşın altındaki hastalarda bunun nedeni sıklıkla herniye bir disk iken, 55 yaş üzerinde spondilotik değişikliklere bağlı gelişen foraminal stenoz ön plandadır. ${ }^{[23]}$ Üst ekstremitede güçsüzlük ve atrofi daha çok herniye disklerde görülürken, parastezi, hiperaljezi, hiperestezi gibi duyusal değişiklikler sıklıkla spondilotik radikülopatide (sert disk) ön plandadır. Yine, reflekslerdeki değişiklikler uzun süreli patolojilerde görüldügüünden, spondilotik radikülopatide de daha sık görülür. Henderson ve arkadaşları, posterolateral foraminatomi yaptıkları servikal radikülopati tanılı 846 hastanın \%99,4'ünde kol ağrısı, \%85,2'sinde duysal defisit, \%79,7'sinde refleks değişiklikleri,
$\% 68$ 'inde motor defisit, \%52,5'inde skapula ağrısı, $\% 17,8$ 'nde sırt ağrısı ve $\% 9,7$ 'sinde baş ağrısı saptamışlardır. ${ }^{[24]}$

Spondilotik miyelopatide şikayetler, basının ağırlık kazandığı ilgili medulla alanına göre değişir; bu da başlangıç dönemlerinde spondilotik miyelopatinin tanısın zorlaştırır. Miyelopatik süreç hızlı ve ilerleyici devam edebildiği gibi, klinik bozulma sonrasında bir stabil dönem ve sonrasında tekrar bozulma şeklinde de görülebilir. Sık görülen şikayetlere bakıldığında; ince motor kayıp (düğme iliklemede zorlanma, yazıda bozulma) yürüyüş bozukluğu, alt ekstremitede katılık sayılabilir. Nadir olarak, idrar ve sfinkter disfonksiyonu görülebilir.

\section{Fizik Muayene}

Hastalara öncelikle tam ve ayrıntılı nörolojik muayene yapılmalıdır. İnce duyu, motor güç ve refleksler gözden geçilmeli, bulgular 1 . motor nöron açısından değerlendirilmelidir. Ardından yapılan özellikli testler, ayırıcı tanıda yardımcı olacaktır.

Davidson tarafindan tanımlanan omuz abduksiyon testi yapılır; omuz abduksiyonu sırasında servikal kök gevşer, radiküler semptomlar rahatlar. ${ }^{[25]}$

Spurling testinde hastanın boynu ekstansiyona alınır ve ağrılı tarafa doğru döndürülerek aksiyel yük uygulanır; bu manevra nöral foramenleri daraltarak semptomları provoke eder.

Miyelopati gelişen hastalarda, uzun yolak bulguları ön plandadır. Artmış kas tonusu, DTR (derin tendon refleksi)'lerde artma, klonus, patolojik reflekslerin varlığı (Babinski ve Hoffmann bulgusu) görülür.

Bununla beraber; Rhee ve arkadaşları, hiperrefleksi, patolojik ve prokovatif testlerin (Hoffmann, Babinski, klonus) servikal miyelopatisi olan hastaların \%20'sinde geçerli olmadığını, görüntüleme yöntemleriyle doğrulanan miyelopatik bulguların tedavi yöntemi seçiminde yeterli olduğunu bildirmişlerdir. ${ }^{[26]}$

\section{Görüntüleme}

\section{Düz grafi}

Düz grafiler, servikal patolojilerin değerlendirmesinde hala önemlidir; basit ve ucuz bir yöntemdir. Sagittal denge, deformite, kırık ve konjenital anomali açısından değerlendirmeyi sağlar. Yine, fleksiyon ve ekstansiyon grafileri servikal kolonun stabilitesi açısından fikir verir.

\section{Tomografi}

Tomografi hızlı ve ayrıntılıdır; özellikle spondilotik değişiklikler göz önünde bulundurulduğunda, kemiksel 
patolojilerin ve osteofitlerin gösterilmesinde oldukça yararlıdır. Foramenlerdeki darlığın, manyetik rezonans (MR) görüntülemeye göre daha iyi değerlendirilmesini sağlar. ${ }^{[27]} Y i n e, 3 D$ rekonstrüksiyon sayesinde deformite açısından da bilgi verir.

\section{$M R$}

MR, yumuşak dokulardaki ayrıntılı görüntüleri sayesinde, servikal bölgenin değerlendirilmesinde en çok kullanılan ve en efektif yöntemdir. Yapılan bir çalışmada, 30 asemptomatik gönüllüye servikal MR çekilmiş ve bu hastaların \%73'ünde diskte taşma, \%50'sinde fokal disk protrüzyonu, \%37'sinde annüler yırtık; 40 yaşın altındakilerin \%25'inde, 40 yaşın üstündekilerin ise \%60'ında dejeneratif disk saptanmıştır. ${ }^{[28]} \mathrm{Bu}$ sonuçlara bakarsak, patoloji daha klinik bulgu vermeden MR bunu yakalayabilmektedir. Servikal patolojilerin değerlendirilmesinde MR anahtar tetkiktir ve mutlaka değerlendirmenin içine alınmalıdır.

\section{DOĞAL GiDiş}

Servikal spondiloz süreci ve prognozunun, hastalığın faktörlerinin çeşitliliği nedeniyle, ön görülmesi belirgin olarak zordur. Clarke ve Robinson, 1956 yılında takip ettikleri ortalama yaşı 53 olan 120 servikal spondilotik hastanın \%75'inde epizodik olarak kötüleşme, \%20 sinde düzenli ilerleme, $\% 5^{\prime}$ inde ise uzun süre stabil giderken aniden semptomlarda kötüleşme saptamışlardır. ${ }^{[29]}$ Lees ve Turner, 1963 yılında 3-40 yıl takip ettikleri servikal spondilotik miyelopati tanılı 44 hastayı değerlendirdikleri yazıda, genel olarak yıllar süren ilerleyici olmayan gidişte defisit olabildiğini, progresif kötüleşmenin çok sık olmadığını bildirmişler, uzun veya kısa dönemler halinde semptomlarda alevlenmeler olabildiği çıkarımını yapmışlardır. ${ }^{[30]}$ Nurick, geriye dönük olarak incelediği 37 hastada, nörolojik arazın erken dönemde ortaya çıktığını ve ardından sıklıkla stabil olarak devam ettiğini, semptomatik ve nörolojik kötüleşmenin 60 yaş üstü hastalarda görüldüğünü ve cerrahi seçeneklerin bu hastalarda değerlendirilebileceğini bildirmiştir. ${ }^{[31]}$ Bununla birlikte, bazı yazarlar, spondilotik miyelopatili hastalarda minör travmalarda ani kötüleşmeler gelişebileceği için, erken dönemde cerrahi önerilebileceğini bildirmektedirler. ${ }^{[32,33]}$ Fouyas ve arkadaşları, spondilotik miyelopatili hastalarda cerrahi tedavi açısından yaptıkları meta-analiz sonucunda, literatürde birbiri ile çelişkili yazıların sayısının çokluğundan ve kesin kanı olmadığından bahsetmektedirler. ${ }^{[34]}$ Kadanka ve arkadaşları, hafif ve orta düzeyde ilerleyici olmayan ya da yavaş ilerleme gösteren SSM'li hastalarda, üç yıllık takipte cerrahi ve konservatif tedavi arasında fark olmadığını bildirmişler ${ }^{[35]}$, Sampath ise, takiplerde cerrahi grubun fonksiyonel olarak çok daha iyi olduğunun bildirmiştir. ${ }^{[36]}$ Bednarik, MR bulgularında spodilolitik servikal kord basısı olan 66 hastanın iki yıllık takiplerinde, \%19,7 servikal miyelopati semptomlarına rastlamıştır. Bu semptomları; servikal radikülopati, elektromiyografide ön boynuz bulguları, anormal somatosensöriyel uyarılmış potansiyel (SEP) bulguları olarak bildirmiştir. Yine, ilerlemenin SEP ile MR'ye göre daha erken tespit edilebildiğini de bildirmiştir. ${ }^{[37,38]}$ Alafifi ve arkadaşları, geriye dönük olarak ameliyat öncesi ve sonrası MR görüntüler karşılaştırılarak yaptıkları çalışma sonrasında, Babinski pozitifliği ve intrensek el kaslarında zayıflık olan hastaların cerrahi öncesi MR görüntülerinde daha güçlü miyelopatik sinyaller olduğu; yine, spastisite ve klonus olan hastalarda cerrahi sonuçların daha kötü olduğu; klonus ve spastisite olmayan hastalarda ise cerrahi sonuçların daha iyi olduğu ve operasyon sonrasında alınan MR görüntülerde belirgin düzelme tespit edildiğini bildirmişlerdir. ${ }^{[39]}$

\section{TARTIŞMA}

Servikal spondiloz, orta ve ileri yaşlardaki popülasyonda sorun yaratan bir patolojidir. Doğal gidişi öngörülemese de, sıklıkla ani bir kötüleşme sonrasında stabil seyreden bir klinik durumdur. Bununla birlikte, hastalığın hızlıca kötüleşebildiği de görülebilir. Sonuç olarak; sadece aksiyel semptomları olan hastalarda, öncelikle konservatif yöntemler tedavi için yeterli olmaktadır. Bununla birlikte, şiddetli ağrısı olan radikülopatili hastalarda cerrahi seçenekler ön plana alınabilir. Cerrahi dekompresyon ve füzyon, özellikle konservatif tedavilere rağmen semptomları devam eden ve ilerleyici nörolojik arazı olan miyelopatili hastalarda düşünülmelidir.

\section{KAYNAKLAR}

1. Roh JS, Teng AL, Yoo JU, Davis J, Furey C, Bohlman $\mathrm{HH}$. Degenerative disorders of the lumbar and cervical spine. Orthop Clin North Am 2005;36(3):255-62. Crossref

2. Asgari S. Cervical spondylotic myelopathy. In: Palmer JD, editor. Neurosurgery 96. Manual of neurosurgery. Edinburgh: Churchill Livingstone; 1996. p.750-4.

3. Rahman S, Than Khoi. Cervical Spondylotic Myelopathy. In: Shen AF, Samartzis D, Fessler R, editors. Textbook of the Cervical Spine. Elsevier Health Sciences; 2014. p.135-45.

4. Ferguson RJ, Caplan LR. Cervical spondylitic myelopathy. Neurol Clin 1985;3(2):373-82.

5. Mercer S, Bogduk N. The ligaments and anulus fibrosus of human adult cervical intervertebral discs. Spine (Phila $\mathrm{Pa}$ 1976) 1999;24(7):619-26.

6. Jurek S, Rao RD. Cervical Spondylosis: Pathophysiology Natural History, and Clinical Syndromes of Neck Pain, Radiculopathy, and Myelopathy. In: Herkowitz H, Grafin S, Eismont F, Bell G, editors. Rothman-Simeone The Spine: Expert Consult. Elsevier Health Sciences; 2011. p.682-94. 
7. Verbiest $\mathrm{H}$. The management of cervical spondylosis. Clin Neurosurg 1973;20:262-94.

8. Chabot MC, Montgomery DM. The pathophysiology of axial and radicular neck pain. Semin Spine Surg 1995;7(1):2-8.

9. Cornefjord M, Olmarker K, Farley DB, Weinstein JN, Rydevik B. Neuropeptide changes in compressed spinal nerve roots. Spine (Phila Pa 1976) 1995;20(6):670-3.

10. White AA 3rd, Panjabi MM. Biomechanical considerations in the surgical management of cervical spondylotic myelopathy. Spine (Phila Pa 1976) 1988;13(7):856-60.

11. Bernhardt MA, Hynes RA, Blume HW, White AA 3rd. Cervical spondylotic myelopathy. J Bone Joint Surg Am 1993;75(1):119-28.

12. Benzel ED. Biomechanics of spine stabilization. Rolling Meadows IL: American Association of Neurological Surgeons Publications; 2001.

13. Hukuda S, Wilson CB. Experimental cervical myelopathy: effects of compression and ischemia on the canine cervical cord. J Neurosurg 197;37(6):631-52. Crossref

14. Bohlman HH, Emery SE. The pathophysiology of cervical spondylosis and myelopathy. Spine (Phila Pa 1976) 1988;13(7):843-6.

15. Henderson FC, Geddes JF, Vaccaro AR, Woodard E, Berry KJ, Benzel EC. Stretch-associated injury in cervical spondylotic myelopathy: new concept and review. Neurosurgery 2005;56(5):1101-13.

16. Baptiste DC, Fehlings MG. Pathophysiology of cervical myelopathy. Spine J 2006;6(6 Suppl):190S-7S. Crossref

17. Yu WR, Baptiste DC, Liu T, Odrobina E, Stanisz GJ, Fehlings MG. Molecular mechanisms of spinal cord dysfunction and cell death in the spinal hyperostotic mouse: implications for the pathophysiology of human cervical spondylotic myelopathy. Neurobiol Dis 2009;33(2):149-63. Crossref

18. Kim RC. Spinal cord pathology. In: Nelson JS, Parisi JE, Schochet SS, editors. Principles and Practice of Neuropathology. St. Louis, MO: CV Mosby; 1993. p.398-435.

19. Côté P, Cassidy JD, Carroll L. The Saskatchewan Health and Back Pain Survey: the prevalence of neck pain and related disability in Saskatchewan adults. Spine (Phila Pa 1976) 1998;23(15):1689-98.

20. Garfin SR. Cervical degenerative disorders: etiology, presentation, and imaging studies. Instr Course Lect 2000;49:335-8.

21. Dwyer A, April C, Bogduk N. Cervical zygapophyseal joint pain patterns. I: A study in normal volunteers. Spine (Phila $\mathrm{Pa}$ 1976) 1990;15(6):453-7.

22. DePalma AF, Subin DK. Study of the cervical syndrome. Clin Orthop Relat Res 1965;38:135-42.

23. Truumees E, Herkowitz HN. Cervical spondylotic myelopathy and radiculopathy. Instr Course Lect 1999;49:339-60.

24. Henderson CM, Hennessy RG, Shuey HM Jr, Shackelford EG. Posterior-lateral foraminotomy as an exclusive operative technique for cervical radiculopathy: a review of 846 consecutively operated cases. Neurosurgery 1983;13(5):504-12.
25. Davidson RI, Dunn EJ, Metzmaker JN. The shoulder abduction test in the diagnosis of radicular pain in cervical extradural compressive monoradiculopathies. Spine (Phila Pa 1976) 1981;6(5):441-6.

26. Fukui M, Chiba K, Kawakami M, Kikuchi S, Konno S, Miyamoto M, Seichi A, Shimamura T, Shirado O, Taguchi T, Takahashi K, Takeshita K, Tani T, Toyama Y, Yonenobu K, Wada E, Tanaka T, Hirota Y. Japanese Orthopaedic Association Cervical Myelopathy Evaluation Questionnaire (JOACMEQ): Part 4. Establishment of equations for severity scores. Subcommittee on low back pain and cervical myelopathy, evaluation of the clinical outcome committee of the Japanese Orthopaedic Association. J Orthop Sci 2008;13(1):25-31. Crossref

27. Freeman TB, Martinez CR. Radiological evaluation of cervical spondylotic disease: Limitation of magnetic resonance imaging for diagnosis and preoperative assessment. Perspect Neurol Surg 1992;3:34-6.

28. Malanga GA. The diagnosis and treatment of cervical radiculopathy. Med Sci Sports Exerc 1997;29(7 Suppl):S236-45.

29. Clarke E, Robinson PK. Cervical myelopathy: a complication of cervical spondylosis. Brain 1956;79(3):483-510.

30. Lees F, Turner JW. Natural history and prognosis of cervical spondylosis. Br Med J 1963;2(5373):1607-10.

31. Nurick $S$. The natural history and the results of surgical treatment of the spinal cord disorder associated with cervical spondylosis. Brain 1972;95(1):101-8.

32. Firooznia $H$, Ahn JH, Rafii M, Ragnarsson KT. Sudden quadriplegia after a minor trauma. The role of preexisting spinal stenosis. Surg Neurol 1985;23(2):165-8.

33. Phillips DG. Surgical treatment of myelopathy with cervical spondylosis. J Neurol Neurosurg Psychiatry 1973;36(5):879-84.

34. Fouyas IP, Statham PF, Sandercock PA. Cochrane review on the role of surgery in cervical spondylotic radiculomyelopathy. Spine (Phila Pa 1976) 2002;27(7):736-47.

35. Kadanka Z, Mareš M, BednaríkJ, Smrcka V, Krbec M, Stejskal L, Chaloupka R, Surelová D, Novotný O, Urbánek I, Dusek L. Approaches to spondylotic cervical myelopathy: conservative versus surgical results in a 3-year follow-up study. Spine (Phila Pa 1976) 2002;27(20):2205-10. Crossref

36. Sampath $P$, Bendebba M, Davis JD, Ducker TB. Outcome of patients treated for cervical myelopathy: a prospective, multicenter study with independent clinical review. Spine (Phila Pa 1976) 2000;25(6):670-6.

37. Bednarik J, Kadanka Z, Dusek L, Novotny O, Surelova D, Urbanek I, Prokes B. Presymptomatic spondylotic cervical cord compression. Spine (Phila Pa 1976) 2004;29(20):2260-9.

38. Bednarik J, Kadanka Z, Dusek L, Kerkovsky M, Vohanka S, Novotny O, Urbanek I, Kratochvilova D. Presymptomatic spondylotic cervical myelopathy: an updated predictive model. Eur Spine J 2008;17(3):421-31. Crossref

39. Alafifi T, Kern R, Fehlings M. Clinical and MRI predictors of outcome after surgical intervention for cervical spondylotic myelopathy. J Neuroimaging 2007;17(4):315-22. Crossref 